\title{
Prevalence and Antibiogram of Microbial Agents Causing Nosocomial Urinary Tract Infection in Surgical Ward of Dhaka Medical College Hospital
}

\author{
Tashmin Afroz Binte Islam ${ }^{1}$, S M Shamsuzzaman ${ }^{2}$, Naznin Nehar ${ }^{3}$, Jannatul Fardows ${ }^{4}$ \\ Received: September 2, 2015 Accepted: April 25, 2016 \\ doi: http://dx.doi.org/10.3329/jemc.v6i2.27761
}

\begin{abstract}
Background: Nosocomial infections pose substantial risk to patients receiving care in hospitals. In Bangladesh, this problem is aggravated by inadequate infection control due to poor hygiene, resource and structural constraints and lack of awareness regarding nosocomial infections. Objective: We carried out this study to determine the prevalence of different microorganisms from urine in surgery ward and antimicrobial susceptibility pattern against various antibiotics. Materials and Methods: This cross sectional study was carried out in Department of Microbiology, Dhaka Medical College, Dhaka over a period of 12 months from July 2011 to June 2012. A total of 52 urine specimens were collected from catheterized patients admitted in general surgery ward of Dhaka Medical College Hospital (DMCH) and incubated in blood agar, MacConkey agar media and the isolates were identified by different biochemical tests - oxidase test and reaction in MIU (motility indole urease) and Simmon's citrate and TSI (triple sugar iron) media. ESBL producers were detected by double-disk synergy test (DDST). Results: Bacteria were isolated from 35 specimens and Escherichia coli was the commonest isolate (23, 65.71\%) followed by Pseudomonas aeruginosa 6 (17.14\%), Klebsiella pneumoniae 3 (8.57\%), Acinetobacter baumannii 2 (5.72\%) and Proteus vulgaris 1 (2.86\%) respectively. Among the isolates, 10 (28.57\%) ESBL producers were detected and the highest ESBL production was observed in Escherichia coli (8, 22.85\%) followed by Klebsiella pneumoniae 1 (2.86\%) and Pseudomonas aeruginosa 1 (2.86\%). The isolates were resistant to most of the commonly used antimicrobial agents. Conclusion: The emergence of multi-drug resistant (MDR) bacteria poses a difficult task for physicians who have limited therapeutic options. However, the high rate of nosocomial infections and multi-resistant pathogens necessitate urgent comprehensive interventions of infection control.
\end{abstract}

Key words: Nosocomial infection; ESBL; Antimicrobial resistance

J Enam Med Col 2016; 6(2): 75-79

\section{Introduction}

Hospital-acquired infections (HAI) have been become a public health problem, creating a new burden recognized for over a century as a critical problem on medical care in hospitals, particularly for patients affecting the quality of healthcare, and these constitute admitted to intensive care units (ICU). ${ }^{1}$

a major source of adverse healthcare outcomes. ${ }^{1,2}$ The In the developed countries, it has been reported to affect emergence of multidrug-resistant bacteria (MDRB) has from 5\% to $15 \%$ of hospitalized patients in regular

1. Assistant Professor, Department of Microbiology, Tairunnessa Memorial Medical College, Gazipur

2. Professor, Department of Microbiology, Dhaka Medical College, Dhaka

3. Lecturer, Department of Virology, Dhaka Medical College, Dhaka

4. Assistant Professor, Department of Microbiology, International Medical College, Gazipur

Correspondence Tashmin Afroz Binte Islam, Email: dr.tasminsomc@gmail.com 
wards and as many as $50 \%$ or more of patients in intensive care units (ICUs) while in developing countries the magnitude of the problem remains largely underestimated. ${ }^{3,4}$ Only few studies have focused on nosocomial infections in developing countries, especially in Bangladesh. 5,6

Urinary-tract infections (UTIs) represent the frequent form of nosocomial infections in developing countries and invasive medical procedures play a major role. ${ }^{6}$ Apart from patient-related factors (e.g., co-infection of other local sites, malnutrition and/or immunedeficiency), the quality of equipment, financial resources as well as the competence of the surgical team seem to be important determinants. ${ }^{7,8}$

The aim of this study was to describe the prevalence of nosocomial urinary tract infections in general surgery ward and the antibiotic resistance profiles of infecting pathogens.

\section{Materials and Methods}

This cross sectional study was carried out in the Department of Microbiology, Dhaka Medical College, Dhaka, Bangladesh. Approval was obtained from Research Review Committee (RRC) and Ethical Review Committee (ERC) of Dhaka Medical College according to declaration of Helsinki and national and institutional standards. Informed written consent was obtained from all participants. A total of 52 urine specimens were collected from catheterized patients from general surgery ward during July, 2011 to June, 2012. Different bacteria were isolated from the specimens and these were examined phenotypically for extended spectrum beta-lactamase (ESBL) production.

Urine collection: Urine was collected from catheter by sterile disposable syringe after proper cleaning of the catheter. Approximately $20 \mathrm{~mL}$ urine was collected aseptically. ${ }^{9}$ The container was properly labelled with patient's name and ID number. The specimens were then transported to the laboratory as quickly as possible.

Isolation of bacteria: All the samples were inoculated on blood agar and MacConkey agar media and incubated at $37^{\circ} \mathrm{C}$ aerobically for 24 hours. The incubated plates were examined for bacterial growth and the organisms were identified by colony morphology, hemolytic criteria, staining character, pigment production and different biochemical tests oxidase test and reaction in MIU (motility indole urease) and Simmon's citrate and TSI (triple sugar iron) media. $^{10}$

Antimicrobial susceptibility testing and screening of ESBL producers: The antimicrobial susceptibility pattern was determined by Kirby Bauer disk-diffusion method on Mueller-Hinton agar using commercially available antibiotic discs (Oxiod, Hampshire, UK) according to CLSI guidelines. ${ }^{11}$ The antibiotic disk used in antibiogram for all the Gram-negative bacteria were co-trimoxazole $(1.25 / 23.75 \mu \mathrm{g})$, gentamicin $(10$ $\mu \mathrm{g})$, ciprofloxacin $(5 \mu \mathrm{g})$, doxycycline $(30 \mu \mathrm{g})$, azithromycin $(30 \mu \mathrm{g})$, amoxiclav $(20+10 \mu \mathrm{g})$, ceftriaxone $(30 \mu \mathrm{g})$, ceftazidime $(30 \mu \mathrm{g})$ and imipenem $(10 \mu \mathrm{g})$. Escherichia coli ATCC 25922 was used for quality control. ESBL producers were screened by diskdiffusion method using ceftazidime and ceftriaxone. If the isolates were resistant to any of these drugs, these were considered as suspected ESBL producers. ${ }^{12}$

Detection of ESBL producers by double-disk synergy test (DDST): ESBL producers were further confirmed for ESBL production by DDST as described below. ${ }^{13}$

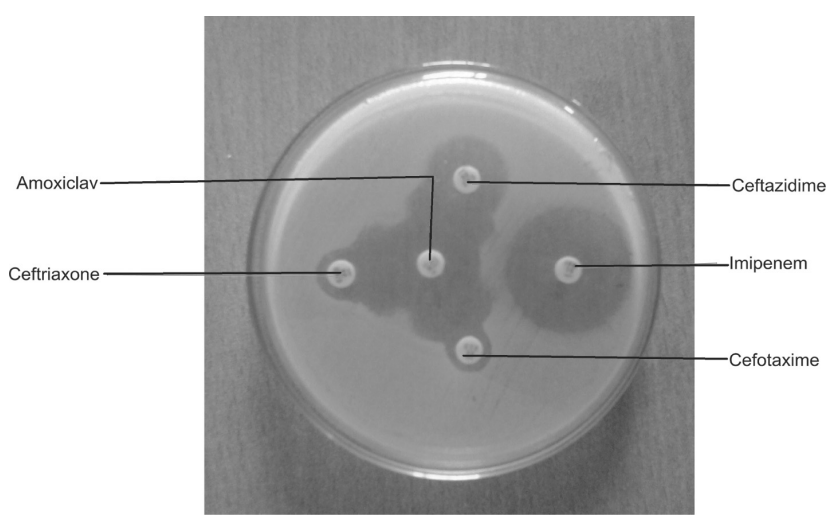

Fig 1. Double-disk synergy test

Mueller-Hinton agar was inoculated with standardized inoculum (corresponding to $0.5 \mathrm{McFarland}$ tube) using sterile cotton swab. An amoxiclav disk was placed on the center of the plate and third generation cephalosporins (ceftriaxone, ceftazidime and cefotaxime disks) were placed at $20 \mathrm{~mm}$ distance (center to center) from the amoxiclav disk. After incubation at $37^{\circ} \mathrm{C}$ for 24 hours, a clear extension of the edge of inhibition zone of any of the three drugs toward amoxiclav disk was interpreted as ESBL producer.

Data analysis: Data were analyzed using Microsoft Excel 2007. 


\section{Results}

Out of the 52 urine specimens, Gram-negative bacilli were isolated from 35 (67.31\%) of which Escherichia coli were the most predominant pathogenic bacteria followed by Pseudomonas aeruginosa, Klebsiella pneumoniae, Acinetobacter baumannii, and Proteus vulgaris (Table II). Among the various Gram-negative bacteria $10(28.57 \%)$ were ESBL producers and mostly was observed in Escherichia coli $(8,22.85 \%)$ followed by Klebsiella pneumoniae 1 (2.86\%) and Pseudomonas aeruginosa 1 (2.86\%).

In this study we found that most UTI cases (54.28\%) were within 41-60 years followed by in the age group of 21-40 years $(31.43 \%)$. ESBL producing uropathogens were found mostly in the age group of 41-60 years (Table III).

Antibiotic susceptibility pattern of isolated bacteria to different antibiotics is shown in Table IV. Most of the organisms were found multidrug resistant but all the isolates were sensitive to imipenem. Isolation rate of different bacteria was found higher among the patients who had more than 15 days hospital stay (Table V).
Table I: Rate of isolation of bacteria from urine specimens $(\mathrm{N}=52)$

\begin{tabular}{|l|c|c|}
\hline Isolated bacteria & Frequency & Percentage \\
\hline Significant growth & 35 & 67.31 \\
\hline No growth & 17 & 32.69 \\
\hline Total & 52 & 100.00 \\
\hline
\end{tabular}

Table II: Organisms isolated from urine $(\mathrm{n}=35)$

\begin{tabular}{|l|c|c|}
\hline Organisms isolated & Number & Percentage \\
\hline Escherichia coli & 23 & 65.71 \\
\hline Pseudomonas aeruginosa & 6 & 17.14 \\
\hline Klebsiella pneumoniae & 3 & 8.57 \\
\hline Acinetobacter baumannii & 2 & 5.72 \\
\hline Proteus vulgaris & 1 & 2.86 \\
\hline Total & 35 & 100.00 \\
\hline
\end{tabular}

Table III: Age distribution of infected patients

\begin{tabular}{|l|c|c|}
\hline Age (years) & Number & Percentage \\
\hline$<20$ & 1 & 2.86 \\
\hline $21-40$ & 11 & 31.43 \\
\hline $41-60$ & 19 & 54.28 \\
\hline$>60$ & 4 & 11.43 \\
\hline Total & 35 & 100.00 \\
\hline
\end{tabular}

Table IV: Antimicrobial resistance pattern of organisms isolated from urine

\begin{tabular}{|c|c|c|c|c|c|}
\hline Antibiotics & $\begin{array}{l}\text { Esch. coli } \\
\text { n }(\%)\end{array}$ & $\begin{array}{c}\text { Klebsiella } \\
\mathrm{n}(\%)\end{array}$ & $\begin{array}{l}\text { Proteus } \\
\text { n (\%) }\end{array}$ & $\begin{array}{c}\text { Pseudomonas } \\
\mathrm{n}(\%)\end{array}$ & $\begin{array}{c}\text { Acinetobacter } \\
\mathrm{n}(\%)\end{array}$ \\
\hline Azithromycin & $15(65.22)$ & $2(66.67)$ & $1(100.00)$ & $5(83.33)$ & $1(50.00)$ \\
\hline Amoxiclav & $16(69.56)$ & $2(66.67)$ & $0(0.00)$ & $4(66.67)$ & $2(100.00)$ \\
\hline Ceftriaxone & $14(60.86)$ & $0(0.00)$ & $0(0.00)$ & $4(66.67)$ & $1(50.00)$ \\
\hline Ciprofloxacin & $19(82.61)$ & $3(100.00)$ & $1(100.00)$ & $5(83.33)$ & $2(100.00)$ \\
\hline Ceftazidime & $13(56.52)$ & $1(33.33)$ & $0(0.00)$ & $3(50.00)$ & $1(50.00)$ \\
\hline Co-trimoxazole & $20(86.95)$ & $2(66.67)$ & $1(100.00)$ & $5(83.33)$ & $1(50.00)$ \\
\hline Doxycycline & 18 (78.26) & $3(100.00)$ & $1(100.00)$ & $5(83.33)$ & $2(100.00)$ \\
\hline Gentamicin & $19(82.61)$ & $2(66.67)$ & $1(100.00)$ & $4(66.67)$ & $2(100.00)$ \\
\hline Imipenem & $0(0.00)$ & $0(0.00)$ & $0(0.00)$ & $0(0.00)$ & $0(0.00)$ \\
\hline
\end{tabular}


Table V: Relationship of culture positivity and duration of hospital stay

\begin{tabular}{|l|c|c|}
\hline Duration & $\begin{array}{c}\text { Positive } \\
\mathrm{n}(\%)\end{array}$ & $\begin{array}{c}\text { Negative } \\
\mathrm{n}(\%)\end{array}$ \\
\hline$<15$ days & $3(8.57)$ & $17(100.00)$ \\
\hline $16-30$ days & $25(71.43)$ & - \\
\hline$>30$ days & $7(20.00)$ & - \\
\hline Total & $35(100.00)$ & $17(100.00)$ \\
\hline
\end{tabular}

\section{Discussion}

Nosocomial infection is affecting the hospitalized patients and creating a major problem in both developed and developing countries. In developed countries many interventions were made to control this but in developing countries like Bangladesh no emphasis has yet been given in this field. In the present study, it was observed that the most common infective organism isolated from postcatheterized UTI cases was Esch. coli (65.71\%) followed by Pseudomonas aeruginosa (17.14\%) and Klebsiella pneumoniae (8.57\%). Earlier studies done in Bangladesh in 1973 and 2010 reported similar predominance of Esch. coli $(37.5 \%$ and $55.9 \%$ respectively) in hospital acquired infections. ${ }^{5,14}$ Similar predominance of Esch. coli and other Gram-negative organisms were reported in hospital acquired infections in Canada. ${ }^{15}$

In the present study, $28.57 \%$ ESBL producers were found in gram-negative bacilli. Some authors from Bangladesh and Iran reported $41.66 \%$ and $47.88 \%$ ESBL producing Gram-negative bacilli in their studies which are higher than findings in this study. ${ }^{6,16}$ The highest ESBL production was observed in Escherichia coli $(34.78 \%)$ which is similar with the findings of a previous study. ${ }^{6}$ The discrepancy in the findings of different studies may be due to the variation in prevalence of ESBL producers with time as well as from country to country, city to city and even hospital to hospital in the same city.

In the present study it was observed that more than $80 \%$ isolated Esch. coli were resistant to ciprofloxacin and gentamicin; this correlates with the findings of another study done in Bangladesh. ${ }^{5}$ In our study, $100 \%$ Klebsiella spp. and Proteus spp. were resistant to ciprofloxacin and doxycycline. The isolated Acinetobacter spp. and Pseudomonas spp. were resistant to most of the commonly used antibiotics and it is similar to results of another study. ${ }^{17}$ We found that all the isolated bacterial strains were $100 \%$ sensitive only to imipenem and it is similar to another study. ${ }^{6}$ This multidrug resistance pattern in Gram-negative organisms might be due to the production of extended spectrum beta-lactamases by Gram-negative organisms. ${ }^{18}$ Increased level of resistance to the commonly used antibiotics in hospital isolates was also reported by others. ${ }^{19,20}$

In a previous study done in Dhaka Medical College Hospital it was found that majority of the patients (41\%) belonged to $45-59$ years of age; it is similar to the findings in our study. ${ }^{21}$ In the present study most of the UTI patients $(54.28 \%)$ were in the age group of 41-60 years. It may be due to decrease in immunity with increase of age.

More drug resistant bacteria were isolated from patients who had prolonged hospital stay. This might be due to the fact that with increase duration of hospital stay, chance of acquiring multidrug resistant bacterial infection is more.

Despite aggressive efforts to limit the rapid rise of antimicrobial resistance, the problem of developing resistance to multiple antibiotics continues to worsen as demonstrated by various studies including the present study. However, the current situation is the result of ineffective infection control measures and antibiotic policies. Large numbers of Gram-negative bacteria causing nosocomial UTIs produce ESBLs with most being multidrug-resistant. Therefore, routine ESBL detection testing and subsequent antibiogram with disk diffusion method could be useful to determine the best treatment options for UTI.

\section{Acknowledgement}

The authors of this paper gratefully acknowledge the technical support provided by Department of Microbiology, Dhaka Medical College, Dhaka.

\section{References}

1. Aly NY, Al-Mousa HH, Al Asar el SM. Nosocomial infections in a medical-surgical intensive care unit. Med Princ Pract 2008; 17: 373-377.

2. Erbay H, Yalcin AN, Serin S, Turgut H, Tomatir E, Cetin B et al. Nosocomial infections in intensive care unit in a Turkish University Hospital: a 2-year survey. Intensive Care Med 2003; 29: 1482-1488. 
3. Nejad SB, Allegranzi B, Syed SB, Ellis B, Pittet D. Healthcare-associated infection in Africa: a systematic review. Bull World Health Organ 2011; 89: 757-765.

4. Vincent JL, Rello J, Marshall J, Silva E, Anzueto A, Martin $\mathrm{CD}$ et al. International study of the prevalence and outcomes of infection in intensive care units. J Am Med Assoc 2009; 302: 2323-2329.

5. Mohiuddin M, Haq JA, Hoq MM, Huq F. Microbiology of nosocomial infection in tertiary hospitals of Dhaka city and its impact. Bangladesh J Med Microbiol 2010; 04: 32-38.

6. Haque R, Salam MA. Detection of ESBL producing nosocomial gram negative bacteria from a tertiary care hospital in Bangladesh. Pak J Med Sci 2010; 26: 887-891.

7. Rosenthal VD, Maki DG, Salomao R, Moreno CA, Mehta Y, Higuera $\mathrm{F}$ et al. Device-associated nosocomial infections in 55 intensive care units of 8 developing countries. Ann Intern Med 2006; 145: 582-591.

8. Anderson DJ, Podgorny K, Berrí os-Torres SI, Bratzler DW, Dellinger EP, Greene L et al. Strategies to prevent surgical site infections in acute care hospitals: 2014 update. Infect Control Hosp Epidemiol 2014; 35: 605-627.

9. Cheesbrough M. District laboratory practice in tropical countries (part 2). $2^{\text {nd }}$ edn. Cambridgeshire, England: ELBS, 2000: 175-180.

10. Baron EJ, Peterson LR, Finegold SM. Enterobacteriaceae. In: Forbes BA, Sahm DF, Weissfeld AS (eds). Bailey and Scott's diagnostic microbiology. $9^{\text {th }}$ edn. St Louis: Mosby, 1994: 374-379.

11. Performance standards for antimicrobial susceptibility testing. Tenth informational supplement. National Committee for Clinical Laboratory Standards (NCCLS), 2000: M100-S10 (M2): 14-21.

12. Centers for Disease Control and Prevention (CDC). Laboratory detection of extended-spectrum b-lactamases (ESBLs). Atlanta: CDC, 2012. [Cited 2015 Mar 12]. Available at: http://www.cdc.gov/HAI/settings/lab/labesbl. html. Accessed August 2015
13. Jarlier V, Nicolas MH, Fournier G, Philippon A. Extended broad-spectrum beta-lactamases conferring transferable resistance to newer-lactam agents in Enterobacteriaceae: hospital prevalence and susceptibility patterns. Rev Infect Dis 1988; 10: 867-878.

14. Ashraf SA, Prodhan A. Study of pattern of infections in the surgical wounds of DMCH. Bangladesh Med Journal 1973; 1: 105-110.

15. Aman S. Bacteriological analysis of wound infection in Mayo hosptial, Lahore. JPMA 1982 March: 66-68.

16. Soltani R, Ehsanpoor M, Khorvash F, Shokri D. Antimicrobial susceptibility pattern of extended-spectrum $\beta$-lactamase-producing bacteria causing nosocomial urinary tract infections in an Iranian referral teaching hospital. J Res Pharm Pract 2014; 3: 6-11.

17. Sikka R, Mann JK, Vashist MG, Chaudhary U, Deep A. Prevalence and antibiotic sensitivity pattern of bacteria isolated from nosocomial infections in a surgical ward. Indian Journal of Clinical Practice 2012; 22: 519-522.

18. Pitout JDD, Thomson KS, Hanson ND, Ehrhardt AF, Moland ES, Sanders CC. Beta Lactamases responsible for resistant to expanded-spectrum cephalosporin in Klebsiella pneumoniae, Esch. coli and Proteus mirabilis isolates recovered in South Africa. Antimicrob Agents Chemother 1998; 42: 1350-1354.

19. Zaman MA, Ahmed ANN, Chowdhury MZU, Ahamed MKU. Surveillance study of hospital acquired infection. J of Bangladesh College of Physicians and Surgeons 1992; 10: 9-13.

20. Jinnah F, Morshed MG, Huq F. Multi resistant Staphylococcus aureus isolated from wound swab of diabetic patients. Journal of Infectious Diseases and Antimicrobial Agents 1998; 15: 15-18.

21. Farukuzzaman. Positive associations of nosocomial infections in surgical ward with aetiological clinical factors. Bratisl Lek Listy 2011; 112: 273-277. 